\title{
The Effect of Co-occurring Heat and Water Stress on Reproductive Traits and Yield of Tomato (Solanum lycopersicum)
}

\author{
Chinedu Felix Amuji ${ }^{1,2 *}$, Linda J. Beaumont ${ }^{1}$ and Brian J. Atwell ${ }^{1}$ \\ ${ }^{1}$ Department of Biological Sciences, Faculty of Science and Engineering, Macquarie University, North Ryde NSW, 2109, Australia \\ ${ }^{2}$ Department of Crop Science, Faculty of Agriculture, University of Nigeria, Nsukka 41001, Enugu State, Nigeria
}

Tomato (Solanum lycopersicum) productivity is negatively impacted by extreme weather events such as heatwaves, flooding and drought. This study evaluated the individual and additive effects of heat and water stress on reproductive traits and yield in the commercial tomato variety 'Roma-VF'. Five weeks after sowing, five stress treatments were introduced consisting of combinations of heat and/or moderate and severe water stress. Heat-stressed plants were subjected to day/night temperatures of $35 / 23^{\circ} \mathrm{C}$, and the control of $28 / 20^{\circ} \mathrm{C}$. Moisture stress was imposed by natural depletion of soil water to $70 \%$ and $40 \%$ of field capacity (moderate and severe stress, respectively). After eight weeks of treatments, plants were placed under control conditions for a five-week recovery phase. Pollen morphology, number of flowers, fruits, and aerial biomass were recorded. Flowers from plants subjected to heat stress combined with either moderate or severe moisture stress did not produce any pollen during the treatment period. Further, by the end of the recovery period, 27$38 \%$ fewer fruits matured on plants subjected to either heat or moisture stress, while fruit production among plants subjected to both stresses simultaneously declined $90 \%$ relative to the control $(P<0.001)$. We conclude that the 'Roma-VF' tomato will be able to recover adequately from heatwaves provided plants are well irrigated. However, should heat and moisture stress co-occur, fruit yield is likely to be decimated and recovery is unlikely. This study is also the first report on additively combined effects of heat and water stress on the 'Roma-VF' tomato.

Key Words: climate change, plant growth, plant reproduction.

\section{Introduction}

Abiotic stresses due to deviations from optimal temperatures, precipitation and relative humidity have been identified as the major climatic variables that have direct impacts on the productivity of crop plants (Ferrante and Mariani, 2018; Onaga and Wydra, 2016). These climatic and atmospheric conditions strongly influence vegetative growth and reproductive success. In crops reliant on sexual reproduction (e.g. seed and fruit production), adverse conditions can also have a profound effect on yield, commonly through a negative impact on gamete development (Dolferus et al., 2013; Zinn et al., 2010).

In addition to climate, extreme temperature events

Received; November 11, 2019. Accepted; May 22, 2020.

First Published Online in J-STAGE on July 23, 2020.

No conflicts of interest declared.

* Corresponding author (E-mail: felix.amuji@gmail.com/felix.amuji @ hdr.mq.edu.au) can also affect yield and, therefore, constrain the geographic range of cultivation (Hatfield and Prueger, 2015). For instance, among tomatoes, one of the world's most common fruit crops (Lu et al., 2019), sustained heat is considered to be a dominant cause of reduced fertility and foregone fruit yield (Peet et al., 1998). Pressman et al. (2002), for example, reported that exposure of tomato plants to $32 / 26^{\circ} \mathrm{C}$ (day/night temperatures) reduced the number and viability of pollen grains in the flowers. Heat stress also causes abortion of microspores, with consequences for subsequent pollen number and viability in tomato (Mesihovic et al., 2016), and therefore compromises fruit set (Firon et al., 2006).

The response of tomato plants to water deficit depends on the genotype, age and stage of development, as well as length and severity of the stress (Wudiri and Henderson, 1985). Studies have shown that withholding water can diminish the number of leaves, branches, flowers, fruits, and even seeds in tomatoes (Jangid and Dwivedi, 2016). 
The combined effect of water and heat stress on plant yields has been studied extensively in chickpea (Awasthi et al., 2014, 2017), lentil (Sehgal et al., 2017) and wheat (Prasad et al., 2011), all of which grow in susceptible regions. While these stresses frequently cooccur in agricultural systems, they can have an impact independently in irrigated fields or temperate dryland agriculture. Recent studies such as Duan et al. (2017), Nankishore and Farrell (2016), and Zhou et al. (2017) focused on the physiological responses of these combined stressors on tomatoes, but did not investigate yield.

In this study, we assess the additive effects of heat and water deficits on reproductive traits and fruit yield in the 'Roma-VF' tomato, a commercial variety that is widely grown in tropical and subtropical regions (Perez et al., 2017). The following hypotheses were tested: (1) heat stress will have a negative effect on pollen grain development and cause a decline in yield, and (2) heatwaves will exacerbate the effects of drought. We report the impact of stress on vegetative growth, working from the premise that compromised leaf area development would affect yield indirectly via carbon metabolism.

\section{Materials and Methods}

\section{Husbandry and growth conditions}

The experiment was carried out in controlled glasshouses at the Plant Growth Facilities (PGF) of Macquarie University, North Ryde campus, Australia (longitude $151^{\circ} \mathrm{E}$; latitude $33^{\circ} \mathrm{S}$ ) during summer in 2018/2019. Tomato seeds ('Roma-VF') were obtained from a local supplier. Seeds were sown directly into 10litre plastic pots containing $11 \mathrm{~kg}$ of uniform sandy-clay texture soil. Ten $g$ of Yates Nutricote Standard Grey ${ }^{\circledR}$ fertilizer (Yates Australia, NSW, Australia) containing NPK (16:4:4 slow release for 70 days) was applied per pot prior to sowing. Three seeds were sown and thinned to one seedling after emergence.

Glasshouses were maintained at a day/night temperature regime of $28 / 20^{\circ} \mathrm{C}$ for five weeks after sowing, following which five treatments and a control, each containing ten replicate pots, were established. For the next eight weeks, three treatments were maintained at a day/night temperature of $35 / 23^{\circ} \mathrm{C}$ (high temperature, HT), while the remainder were kept at $28 / 20^{\circ} \mathrm{C}$ (control temperature, CT) (details of the day/night temperature regimes are described in the following section). Simultaneously, two treatments were subjected to water stress by allowing soil water to reduce to $70 \%$ soil field ca- pacity (moderate stress), while another two treatments were subjected to $40 \%$ soil water field capacity (severe stress). The fifth and sixth treatments were fully irrigated ( $\sim 100 \%$ field capacity). Pots were watered daily to maintain soil moisture at the set field capacities for each pot. Water application was carefully done manually throughout the eight weeks of treatments, following the concept of maintaining soil moisture with both mass and volume fractions. The soil water deficit was defined as the quantity of water needed to return the water content to its equilibrium volume after saturation and subsequent natural drainage (Russell and Russell, 1988). A 12-hour photoperiod with minimum light levels of $600 \mu \mathrm{mol} \cdot \mathrm{m}^{-1} \cdot \mathrm{s}^{-1}$ and $\mathrm{CO}_{2}$ concentration of $400 \mathrm{ppm}$ (parts per million) was maintained throughout the experiment. A completely randomized design (CRD) was adopted within the two glasshouses used for this experiment. One of the glasshouses was programmed to the heat stress temperature only during the treatment period, after which both were maintained under the control temperatures conditions. All treatments together with the control conditions as summarized in Table 1 had 10 sampling plants each, which also served as the replicates. After termination of treatments, plants were returned to water supply and temperature control conditions for five weeks in order to assess recovery (see Table 1).

\section{Temperature regimes}

The temperature of 'control' glasshouses was maintained as follows: $20^{\circ} \mathrm{C}$ from 23:00 to $04: 00$, followed by a $0.5^{\circ} \mathrm{C}$ increase every $30 \mathrm{~min}$ from $04: 00$ then remaining constant at $28^{\circ} \mathrm{C}$ until 17:00 (i.e. $5 \mathrm{pm}$ local time). Temperature was then decreased by $0.5^{\circ} \mathrm{C} /$ $30 \mathrm{~min}$, returning to the minimum night-time temperature of $20^{\circ} \mathrm{C}$. For high temperature treatments, temperature within glasshouses was increased by $1{ }^{\circ} \mathrm{C}$ /hour starting at 04.00 from the minimum night temperature of $23^{\circ} \mathrm{C}$, to reach the daily maximum of $35^{\circ} \mathrm{C}$. After 17.00 (i.e. $5 \mathrm{pm}$ local time), temperature was reduced at the same rate from 17:00 until the minimum temperature was reached.

\section{Data collection}

New flowers that developed on each sampling plant were counted weekly starting from the sixth to thirteenth weeks after planting (i.e. the first to eight weeks of treatment) and from the fourteenth to eighteenth weeks after planting (i.e. the first to the fifth week of

Table 1. Growth conditions for the control and treatments used to assess the impacts of heat and water stress on Roma-VF tomatoes.

\begin{tabular}{lcccccc}
\hline \hline & Control & Heat alone & Heat stress +MWS & Heat stress +SWS & Moderate +WS & Severe +WS \\
\hline Temperature (day/night) & $28 / 20^{\circ} \mathrm{C}$ & $35 / 23^{\circ} \mathrm{C}$ & $35 / 23^{\circ} \mathrm{C}$ & $35 / 23^{\circ} \mathrm{C}$ & $28 / 20^{\circ} \mathrm{C}$ & $28 / 20^{\circ} \mathrm{C}$ \\
Water level (\% field capacity) & $100 \%$ & $100 \%$ & $70 \%$ & $40 \%$ & $70 \%$ & $40 \%$ \\
\hline
\end{tabular}

$\mathrm{MW}=$ Moderate water stress, $\mathrm{SW}=$ Severe water stress, $\mathrm{n}=10$ plants for each treatment. 
the recovery phase). At the conclusion of the experiment in the eighteenth week after planting, we measured the total leaf area per plant using an LI-3100C Area Meter machine (LI-COR, Lincoln, NE, USA), as well as shoot biomass and number of developed fruits.

\section{Reproductive traits}

Within each treatment, in the thirteenth week after planting (i.e. eight weeks of treatment), a total of five flowers were harvested from five plants and viewed under a light microscope (Olympus SX16 Zoom Stereo Microscope, Objectives at $1 \times$ and $2 \times$, transmitted, collar and gooseneck LED-illuminated, mounted with a colour digital camera, Olympus DP26, powered by CellSens imaging software; Olympus, Tokyo, Japan). Pollen from each treatment was observed and compared using a scanning electron microspore (JEOL 6480LA SEM-Tungsten Variable Pressure. Equipped with an EX-94300 SDD Energy Dispersive X-ray analyser and a Deben Cool stage; JEOL Ltd., Tokyo, Japan).

\section{Statistical analysis}

The collected data were statistically analysed by ANOVA using Minitab 18.1 software (Minitab Inc., PA, USA), while the differences between control and stress treatments were assessed according to Tukey's range test at a $1 \%$ and $5 \%$ level of significance. "Ggplot" package (Wickham, 2016) was used for the graphical presentation of data in R-studio version 3.6.1 ( $\mathrm{R}$ Development Core Team, 2019).

\section{Results}

Fewer flowers developed during the eight-week treatment period due to water and heat stress treatments $\left(P<0.001, d f=5, f\right.$-value $\left.=53.06, r^{2}=91.7\right)$, with the effects of these stresses seen more or less cumulatively during treatment (Fig. 1). Heat combined with severe water stress resulted in substantially fewer flowers over eight weeks (cumulated mean $=4 \pm 1.9 \mathrm{SD}$ ) than the other treatments (e.g. control cumulated mean $=81.2 \pm$ 8.9 SD). Notably, plants in the heat + severe water stress treatment group (cumulated mean $=5.4 \pm 4.3 \mathrm{SD}$, $P=0.09$ ) failed to recover after returning to control conditions (Fig. 2). In contrast, no statistically significant difference was seen between the number of flowers that developed under control conditions and the individual heat or water stress treatments by the end of the recovery period on the plants (Control cumulated mean $=$ $41.8 \pm 11 \mathrm{SD}$, Heat stress $=34 \pm 6.7 \mathrm{SD}$, Water stress $=$ 25.6-33.2 $\pm 3.6-13.7$ SD, Fig. 2). While flower sepals, petals and the anthers formed normally among control plants, under heat + severe water stress, flowers remained closed, with petals and anthers always enclosed by sepals (Fig. 3a, b).

Scanning electron microscope images showed that under heat + severe water stresses pollen was not visible (Fig. 4). However, no morphological differences

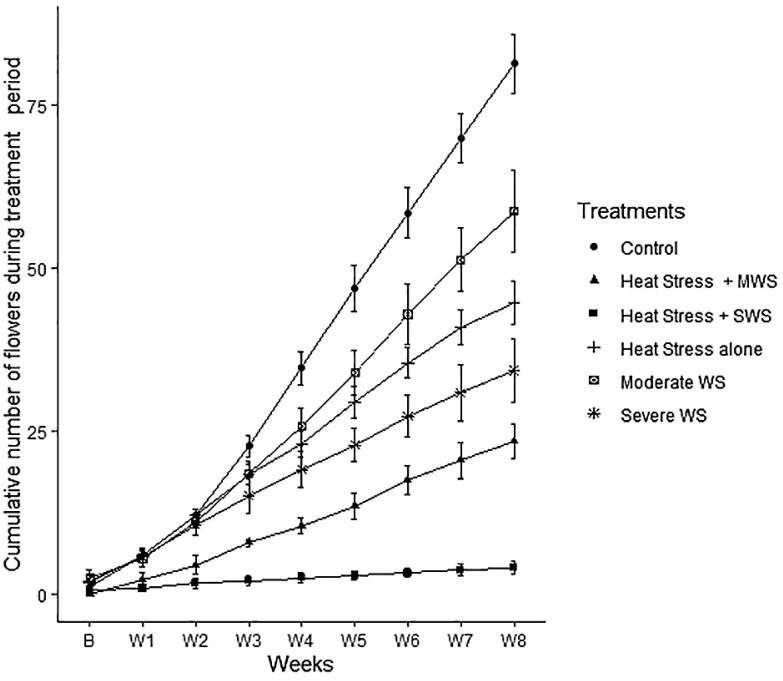

Fig. 1. Cumulative number of flowers produced weekly from Roma tomatoes during the treatment period. Vertical bars represent \pm standard error, while dots represent the mean. MWS $=$ Moderate water stress, $\mathrm{SWS}=$ Severe water stress, and WS $=$ Water stress, $\mathrm{B}=$ start of the treatments, W1-W8 = consecutive weeks of treatment, corresponding to the 6th-13th week after planting, respectively, $\mathrm{n}=10$ plants for each treatment.

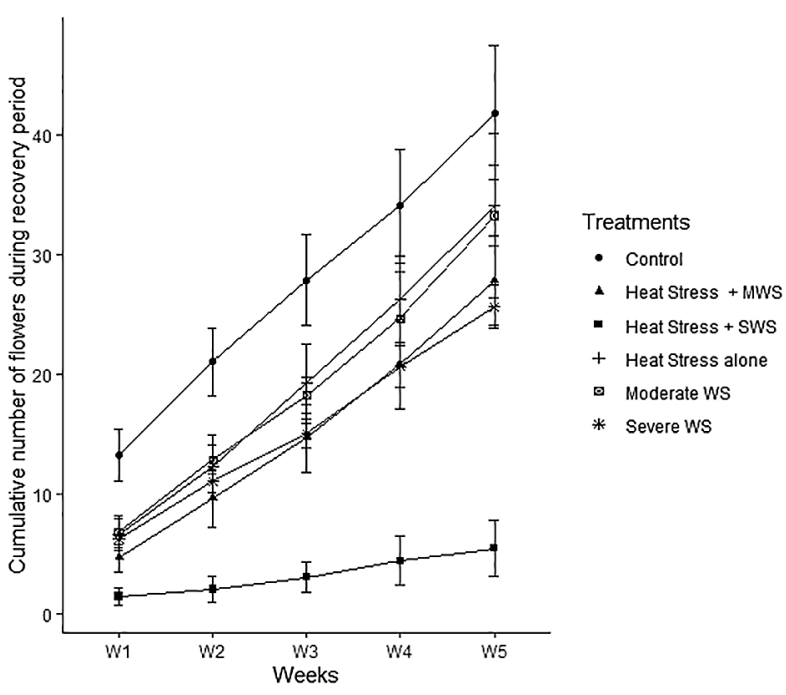

Fig. 2. Cumulative number of flowers produced weekly from Roma tomatoes during the recovery period. Vertical bars represent \pm standard error, while dots represent the mean. MWS $=$ Moderate water stress, $\mathrm{SWS}=$ Severe water stress and WS $=$ Water stress, W1-W5 = consecutive weeks of recovery, corresponding to the 14th-18th week after planting, respectively, $\mathrm{n}=10$ plants for each treatment.

were observed on the surface of pollen grains expose to either heat or water stress alone (data not shown).

The number of fruits that developed decreased significantly by $33 \%$ solely due to heat treatment and between $27-38 \%$ under the two water stress treatments when applied without heat $(P<0.001)$. When these stresses were combined, there was up to a $90 \%$ reduction in the number of fruits produced compared with the 
control $(P<0.001)$ (Fig. 5).

By itself, heat stress did not affect stem and leaf weights compared with the control plants. However, both fresh and dry stem and leaf weights were significantly reduced among plants exposed to heat + water stress $(P<0.005$; Fig. 6). When applied individually, neither heat nor water stress resulted in significant re-

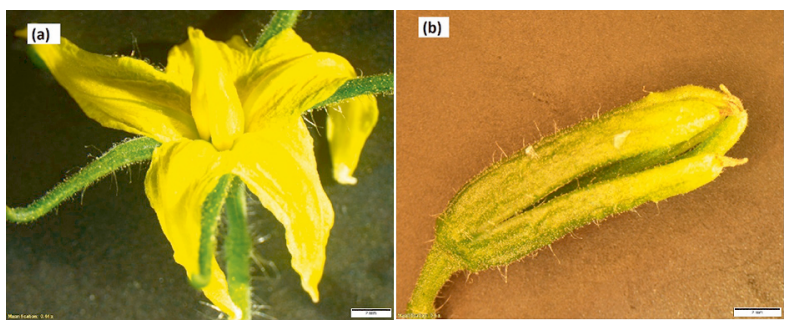

Fig. 3. Light micrograph of the impact of heat + severe water stress on the Roma flowers (b) compared with that of the control (a). Magnification $2 \times$. Observed in the last (eighth) week of treatment.
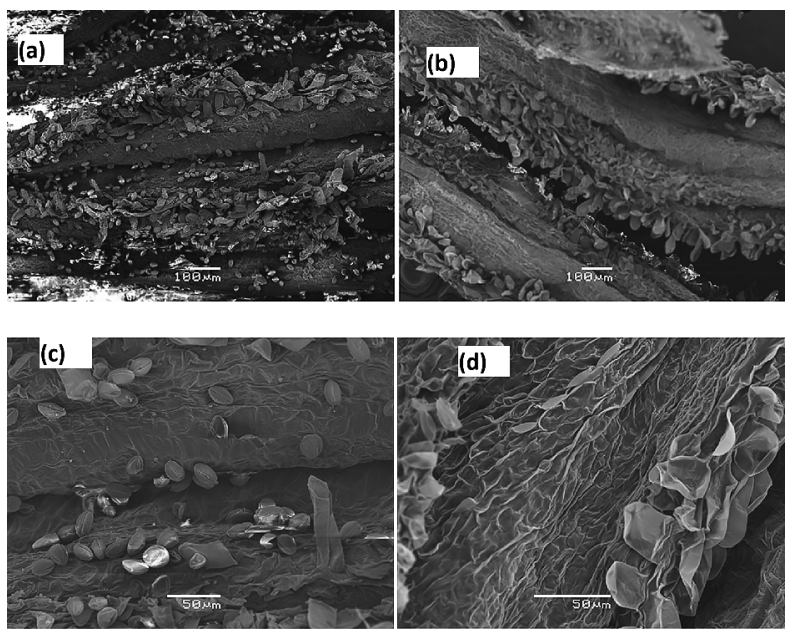

Fig. 4. Scanning electron micrograph of Roma pollen under control conditions (a and c) and (b and d) heat + severe water stress conditions, magnification $1,000 \times(\mathrm{a}$ and $\mathrm{b})$ and $5,000 \times(\mathrm{c}$ and d). Observed in the last (eighth) week of treatment. ductions to the total leaf area per plant. However, heat when combined with severe water stress reduced the total leaf area significantly $(P<0.033$; Table 2$)$.

The proportion of flowers that developed into fruit served as an indicator of successful fertilisation. The highest proportion occurred among the control plants, for which an average of $10 \%( \pm 2 \% \mathrm{SD})$ of flowers developed fruit (number of fruits at the end of the recovery period divided by cumulative number of flowers). This did not differ significantly from plants subjected to moderate $(9 \% \pm 4 \%)$ or severe water stress $(8 \% \pm 1 \%)$, or heat stress alone $(7 \% \pm 3 \%)$. This indicates that heat stress impaired flower fertility. Treatments that combined both heat and water stress resulted in a more dramatic reduction in the proportion of flowers that were fertilised and went on to develop into fruit $(2 \% \pm 2 \%)$ compared with control plants $(P<0.001$; Table 2$)$.

\section{Discussion}

We herein report the impacts of heat and moisture stress, both individually and combined, on flowering, fruit yield and biomass of Roma-VF tomatoes. These stresses have major impacts on tomato production in field conditions globally (Maiti et al., 2008), and given that temperature extremes and moisture deficits are likely to increase as the century progresses (Bradford et al., 2017), our quantitative analysis is timely. Unsurprisingly, vegetative growth of Roma plants was affected by these abiotic stresses; however, our results (Fig. 6) indicate that this impact was modest unless heat was combined with severe water stress. Similar findings were reported by Nankishore and Farrell (2016) in tomatoes and Correia et al. (2018) in Eucalyptus globulus.

Floral development was a more sensitive trait than the vegetative parts, as assessed by the number of flowers that matured (Figs. 1 and 2), pollen integrity (Fig. 4) and the proportion of flowers that were fertilised and produced fruit (Table 2). Apart from the obvious significance of these data for food production, we explored

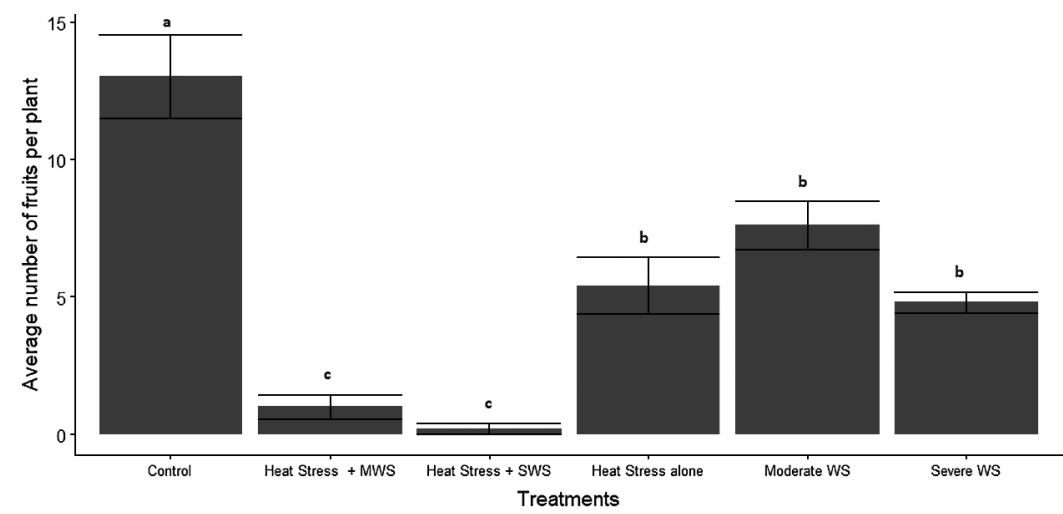

Fig. 5. Average number of fruits produced per Roma tomato plant under five combinations of heat and water stress, and the control. Vertical bars denote $\pm \mathrm{SE}$ of mean. Means with different letters are significantly different according to Tukey's HSD at $P<0.01$. MWS $=$ Moderate water stress, $\mathrm{SWS}=$ Severe water stress and WS $=$ Water stress, $\mathrm{n}=$ ten plants for each treatment. Measured in the 18th week after planting. 

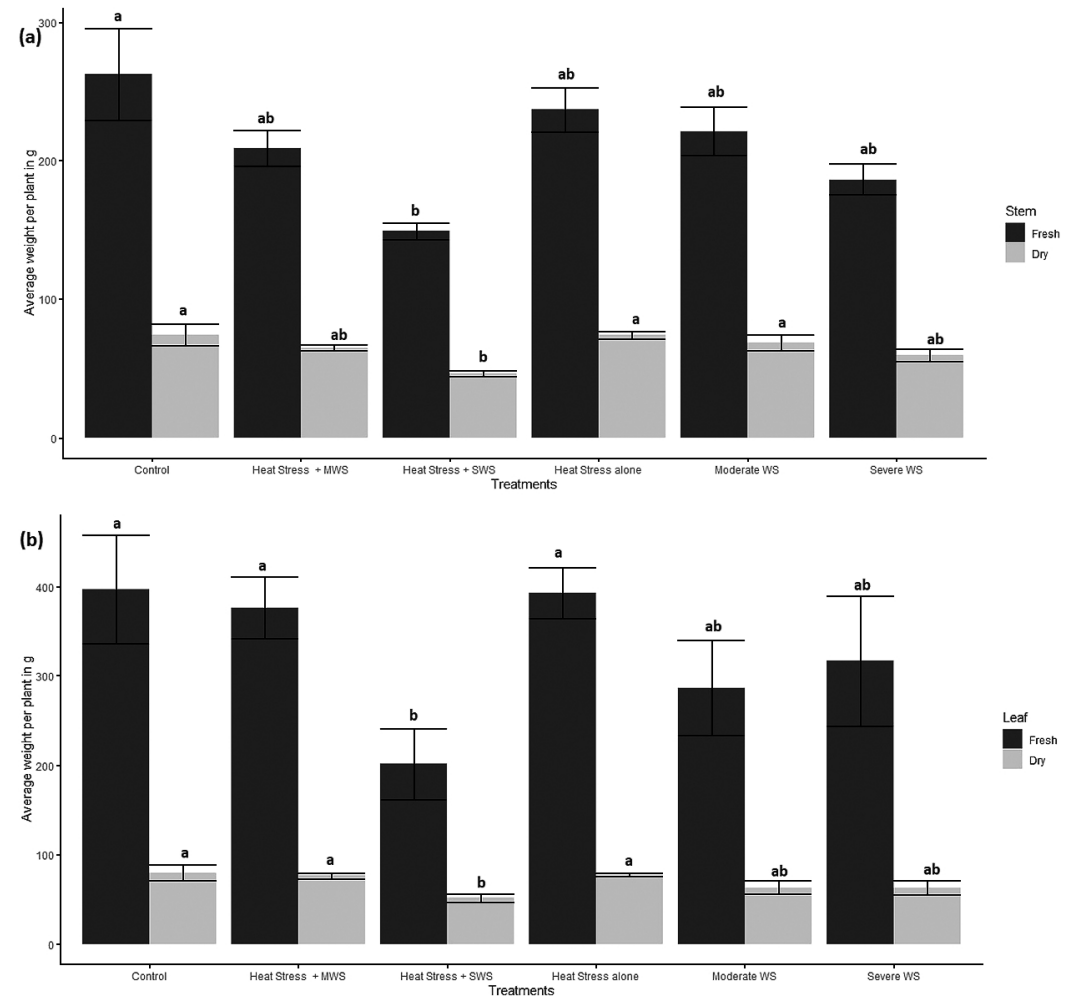

Fig. 6. Total fresh and dry biomass weight of the stems (a) and leaves for each tomato plant (b) across the control and five heat and/or water stress treatments. Vertical bars denote \pm SE of mean. Means with different letters are significantly different according to Tukey's HSD at $P<$ 0.05 . MWS $=$ Moderate water stress, $\mathrm{SWS}=$ Severe water stress and WS $=$ Water stress, $\mathrm{n}=$ ten plants for each treatment. Measured in the 18 th week after planting.

Table 2. Effect of the treatments on the fruit set ratios and total leaf area in $\mathrm{cm}^{2}$ of the Roma-VF plants.

\begin{tabular}{|c|c|c|}
\hline Treatments & $\begin{array}{c}\text { Percent fruit set } \\
\frac{\text { Total number of fruits developed }}{\text { Total cumulative number of flowers }} \times 100\end{array}$ & Total leaf area in $\mathrm{cm}^{2}$ \\
\hline Control & $10.4 \pm 2.0^{\mathrm{a}}$ & $8394 \pm 140^{\mathrm{a}}$ \\
\hline Heat stress + MWS & $2.0 \pm 2.0^{\mathrm{b}}$ & $6578 \pm 60^{\mathrm{b}}$ \\
\hline Heat stress + SWS & $1.6 \pm 4.0^{\mathrm{b}}$ & $3951 \pm 110^{c}$ \\
\hline Heat stress alone & $6.9 \pm 3.0^{\mathrm{ab}}$ & $7223 \pm 140^{\mathrm{ab}}$ \\
\hline Moderate WS & $8.9 \pm 4.0^{\mathrm{a}}$ & $6229 \pm 120^{\mathrm{ab}}$ \\
\hline Severe WS & $8.1 \pm 1.0^{\mathrm{a}}$ & $6674 \pm 240^{\mathrm{ab}}$ \\
\hline F-value & 7.82 & 2.94 \\
\hline$P$-value & $<0.001$ & 0.033 \\
\hline
\end{tabular}

MWS $=$ Moderate water stress, $\mathrm{SWS}=$ Severe water stress and WS $=$ Water stress, $\mathrm{n}=10$ plants for each treatment. Mean values with the same letter are not significantly different at $P<0.05$ according to Tukey's test, $P$ and F-values indicate the level of significance among the treatments. Measured in the 18 th week after planting.

the qualitative distinction between reproductive development and earlier vegetative growth.

Flowers are sink organs that make use of carbohydrates produced by the plants via photosynthesis (Lemoine et al., 2013). Plant sinks are always vulnerable to extremes of heat and moisture during development because of resource limitations (Sawicki et al., 2015). Any restriction in the supply of essential photosynthetic resources can impair floral development and induce flower abortion (Descamps et al., 2018).
Sevanto (2014) reported failure of phloem transport as a result of water stress, affecting supply to plant sink organs.

A critical impact of abiotic stress is the sensitivity of pollen development and the subsequent impact on fertilisation. This phenomenon has been widely reported in multiple species (Zinn et al., 2010), but little information is available for combined heat and water stress effects on tomato pollens. Abiotic stresses can influence flower production and development, even when plants 
maintain near-optimal growth and physiological status (Descamps et al., 2018).

Reproductive development in Roma-VF plants was profoundly aggravated by the combination of heat and severe water stress and even individual stresses had a significant impact on reproductive physiology, reducing flower numbers and fruit set by about $50 \%$ at the end of the treatment period (Fig. 5). Heat and water stress both affected the developmental transition of flowers to fruit by a lesser extent, with 7-9\% fruit set as compared with $10 \%$ in control plants (Table 2). This suggests that if flowers can form under these stresses, more than half are likely to undergo fertilisation and make fruit. In general, these data reflect the warm temperate range typical of tomatoes (Schwarz et al., 2014).

Heat and water stresses can affect the fertility of plants particularly by impairing stamen development (Smith and Zhao, 2016) (also see Fig. 4). Indeed, in tomatoes male organs appear more susceptible to abiotic stresses than female organs (Smith and Zhao, 2016). Interestingly, neither heat nor water stress alone, as used in our experiment, affected the morphology of pollen grains compared with control conditions. However, the combination of these stressors negatively impacted pollen developing during the treatment phase of the experiment (data not shown). Pressman et al. (2002) also observed a reduction in the number pollen grain in tomatoes as a result of heat stress at $32 / 26^{\circ} \mathrm{C}$ day/night temperature. Water stress can prevent pollen development by creating a condition that causes adenosine triphosphate (ATP) depletion due to the presence of induced reactive oxygen species (ROS) (Nguyen et al., 2009). Pollen defects and consequent male sterility due to elevated temperature effects in the meiotic stage have been noted in tomatoes (Iwahori, 1966), cowpea (Ahmed et al., 1992) and wheat (Omidi et al., 2014). The ability of heat stress to induce meiotic abnormality and the depletion of ATP due to water stress may have prevented the Roma plants, under these combined stressors, from producing pollen grains.

We also found that the combination of heat and water stress significantly reduced the vegetative growth of the tomato plants more than the individual stresses (Fig. 6). This was contrary to Zhou et al. (2017) who reported that these combined stresses did not cause any difference in the vegetative growth of tomatoes. We note, however, that Zhou et al. (2017) used different varieties to Roma, maintained their treatments at a lower daytime temperature $\left(32 / 26^{\circ} \mathrm{C}\right.$ day/night), and imposed both heat and water stress for a shorter period of time (5 days) compared to our experiment. Studies on other crops, such as chickpea (Awasthi et al., 2014) and barley (Rollins et al., 2013), have also demonstrated that combined heat and water stress can have greater negative impacts on plant growth and yield than individual stresses. The declines in yield (represented in this experiment as number of developed fruits see Fig. 5) were attributed to the negative impact of stresses on the observed crop reproductive developmental stages (Figs. 3 and 4).

The end product of tomato cultivation is fruit production. Our results demonstrated fruit production to be significantly reduced under the combined heat and water stress treatment (Fig. 5). There was a coordinated involvement of flower and pollen development in impacting fruit yield, suggesting that several components function together in influencing the plant's response to combined stresses (Figs. 3, 4, and 5). This is similar Sehgal et al.'s (2017) findings that combined heat and water stress affected many components of lentil development which invariably combined to reduce seed yield. There is a further need to identify tomato genotypes that are tolerant to these combined heat and water stress conditions as used in this experiment.

\section{Conclusion}

Our study showed that Roma-VF tomatoes suffered greatly from heat stress for eight weeks due to addition of water deficit extremes even after been given a fiveweek recovery period. By the end of the recovery phase, heat or water stress alone caused a reduction in fruit yield, but not vegetative biomass, while the combination of heat and water stress severely inhibited flower production, vegetative biomass and fruit development.

\section{Literature Cited}

Ahmed, F. E., A. E. Hall and D. A. DeMason. 1992. Heat injury during floral development in cowpea (Vigna unguiculata, Fabaceae). Am. J. Bot. 79: 784-791.

Awasthi, R., P. Gaur, N. C. Turner, V. Vadez, K. H. Siddique and H. Nayyar. 2017. Effects of individual and combined heat and drought stress during seed filling on the oxidative metabolism and yield of chickpea (Cicer arietinum) genotypes differing in heat and drought tolerance. Crop Pasture Sci. 68: 823-841.

Awasthi, R., N. Kaushal, V. Vadez, N. C. Turner, J. Berger, K. H. Siddique and H. Nayyar. 2014. Individual and combined effects of transient drought and heat stress on carbon assimilation and seed filling in chickpea. Funct. Plant Biol. 41: $1148-1167$.

Bradford, J. B., D. R. Schlaepfer, W. K. Lauenroth, C. B. Yackulic, M. Duniway, S. Hall, G. Jia, K. Jamiyansharav, S. M. Munson, S. D. Wilson and B. Tietjen. 2017. Future soil moisture and temperature extremes imply expanding suitability for rainfed agriculture in temperate drylands. Sci. Rep. 7: 12923. DOI: 10.1038/s41598-017-13165-x.

Correia, B., R. D. Hancock, J. Amaral, A. Gomez-Cadenas, L. Valledor and G. Pinto. 2018. Combined drought and heat activates protective responses in Eucalyptus globulus that are not activated when subjected to drought or heat stress alone. Front. Plant Sci. 9: 819. DOI: 10.3389/fpls.2018.00819.

Descamps, C., M. Quinet, A. Baijot, J. V. Dongen and A. L. Jacquemart. 2018. Temperature and water stress affect plant-pollinator interactions in Borago officinalis (Boraginaceae). Ecol. Evol. 8: 3443-3456.

Dolferus, R., N. Powell, J. Xuemei, R. Ravash, J. Edlington, S. Oliver, J. V. Dongen and B. Shiran. 2013. The physiology of reproductive-stage abiotic stress tolerance in cereals. In: G. 
Rout and A. Das (eds.). Molecular Stress Physiology of Plants. Springer, India. DOI: 10.1007/978-81-322-0807-5_8.

Duan, H., J. Wu, G. Huang, S. Zhou, W. Liu, Y. Liao, X. Yang, Z. Xiao and H. Fan. 2017. Individual and interactive effects of drought and heat on leaf physiology of seedlings in an economically important crop. AoB Plants 9: DOI: 10.1093/ aobpla/plw090.

Ferrante, A. and L. Mariani. 2018. Agronomic management for enhancing plant tolerance to abiotic stresses: High and low values of temperature, light intensity, and relative humidity. Horticulturae 4: 21. DOI: 10.3390/horticulturae4030021.

Firon, N., R. Shaked, M. Peet, D. Pharr, E. Zamski, K. Rosenfeld, L. Althan and E. Pressman. 2006. Pollen grains of heat tolerant tomato cultivars retain higher carbohydrate concentration under heat stress conditions. Sci. Hortic. 109: 212-217.

Hatfield, J. L., L. Althan and J. H. Prueger. 2015. Temperature extremes: Effect on plant growth and development. Weather Clim. Extremes 10: 4-10.

Iwahori, S. 1966. High temperature injuries in tomato. V. J. Japan. Soc. Hort. Sci. 35: 379-386.

Jangid, K. K. and P. Dwivedi. 2016. Physiological responses of drought stress in tomato: a review. Int. J. Agric. Environ. Biotechnol. 9: 53-61.

Lemoine, R., S. La Camera, R. Atanassova, F. Dédaldéchamp, T. Allario, N. Pourtau, J. L. Bonnemain, M. Laloi, P. CoutosThévenot, L. Maurousset, M. Faucher, C. Girousse, P. Lemonnier, J. Parrilla and M. Durand. 2013. Source-to-sink transport of sugar and regulation by environmental factors. Front. Plant Sci. 4: 272. DOI: 10.3389/fpls.2013.00272.

Lu, J., G. Shao, J. Cui, X. Wang and L. Keabetswe. 2019. Yield, fruit quality and water use efficiency of tomato for processing under regulated deficit irrigation: A meta-analysis. Agric. Water Manag. 222: 301-312.

Maiti, R., B. Amitava and N. Sarkar. 2008. Abiotic factors affecting tomato productivity, mechanisms of adaptation and management strategy. Int. J. Agric. Environ. Biotechnol. 1: 9-35.

Mesihovic, A., R. Iannacone, N. Firon and S. Fragkostefanakis. 2016. Heat stress regimes for the investigation of pollen thermotolerance in crop plants. Plant Reprod. 29: 93-105.

Nankishore, A. and A. D. Farrell. 2016. The response of contrasting tomato genotypes to combined heat and drought stress. J. Plant Physiol. 202: 75-82.

Nguyen, G. N., D. L. Hailstones, M. Wilkes and B. G. Sutton. 2009. Drought-induced oxidative conditions in rice anthers leading to a programmed cell death and pollen abortion. J. Agron. Crop Sci. 195: 157-164.

Omidi, M., M. R. Siahpoosh, R. Mamghani and M. Modarresi. 2014. The influence of terminal heat stress on meiosis abnormalities in pollen mother cells of wheat. Cytologia 79: 49-58.

Onaga, G. and K. Wydra. 2016. Advances in plant tolerance to abiotic stresses. Plant Genomics: 229-272.

Peet, M., S. Sato and R. Gardner. 1998. Comparing heat stress effects on male-fertile and male-sterile tomatoes. Plant Cell Environ. 21: 225-231.

Perez, K., J. S. Froikin-Gordon, I. K. Abdourhamane, V. Levasseur, A. A. Alfari, A. Mensah, O. Bonsu, B. Habsatou,
F. Assogba-Komlan, A. A. Mbaye, M. Noussourou, L. C. Otoidobiga, L. Ouédraogo, T. Kon, M. R. Rojas, K. T. Gamby, F. Shotkoski, R. L. Gilbertson and M. M. Jahn. 2017. Connecting smallholder tomato producers to improved seed in West Africa. Agric. Food Secur. 6: 42. DOI: 10.1186/ s40066-017-0118-4.

Prasad, P., S. Pisipati, I. Momčilović and Z. Ristic. 2011. Independent and combined effects of high temperature and drought stress during grain filling on plant yield and chloroplast EF-Tu expression in spring wheat. J. Agron. Crop Sci. 197: 430-441.

Pressman, E., M. M. Peet and D. M. Pharr. 2002. The effect of heat stress on tomato pollen characteristics is associated with changes in carbohydrate concentration in the developing anthers. Ann. Bot. 90: 631-636.

R Development Core Team. 2019. R: A Language and Environment for Statistical Computing (Version 3.6.1). Vienna, Austria. $<$ https://www.R-project.org/>.

Rollins, J., E. Habte, S. Templer, T. Colby, J. Schmidt and M. Von Korff. 2013. Leaf proteome alterations in the context of physiological and morphological responses to drought and heat stress in barley (Hordeum vulgare L.). J. Exp. Bot. 64: 3201-3212.

Russell, E. J. and E. W. Russell. 1988. Russell's soil conditions and plant growth (11 ed.). A. Wild (ed.). Longmans Scientific and Technical. Essex, England.

Sawicki, M., E. Aït Barka, C. Clément, N. Vaillant-Gaveau and C. Jacquard. 2015. Cross-talk between environmental stresses and plant metabolism during reproductive organ abscission. J. Exp. Bot. 66: 1707-1719.

Schwarz, D., A. J. Thompson and H. P. Kläring. 2014. Guidelines to use tomato in experiments with a controlled environment. Front. Plant Sci. 5: 625. DOI: 10.3389/fpls.2014.00625.

Sehgal, A., K. Sita, J. Kumar, S. Kumar, S. Singh, K. H. Siddique and H. Nayyar. 2017. Effects of drought, heat and their interaction on the growth, yield and photosynthetic function of lentil (Lens culinaris Medikus) genotypes varying in heat and drought sensitivity. Front. Plant Sci. 8: 1776. DOI: 10.3389/fpls.2017.01776.

Sevanto, S. 2014. Phloem transport and drought. J. Exp. Bot. 65: 1751-1759.

Smith, A. R. and D. Zhao. 2016. Sterility caused by floral organ degeneration and abiotic stresses in Arabidopsis and cereal grains. Front. Plant Sci. 7: 1503.

Wickham, H. 2016. ggplot2: elegant graphics for data analysis. Springer-Verlag, New York.

Wudiri, B. B. and D. Henderson. 1985. Effects of water stress on flowering and fruit set in processing-tomatoes. Sci. Hortic. 27: 189-198.

Zhou, R., X. Yu, C. O. Ottosen, E. Rosenqvist, L. Zhao, Y. Wang and Z. Wu. 2017. Drought stress had a predominant effect over heat stress on three tomato cultivars subjected to combined stress. BMC Plant Biol. 17: 24.

Zinn, K. E., M. Tunc-Ozdemir and J. F. Harper. 2010. Temperature stress and plant sexual reproduction: uncovering the weakest links. J. Exp. Bot. 61: 1959-1968. 